\title{
Creativity on Icon Design of Mobile Apps
}

\author{
Kungpo Tao \\ Elizabeth City State University, Elizabeth City, North Carolina, USA \\ Email: ktao@ecsu.edu
}

How to cite this paper: Tao, K.P. (2019) Creativity on Icon Design of Mobile Apps. Theoretical Economics Letters, 9, 2756-2770. https://doi.org/10.4236/tel.2019.98173

Received: August 9, 2019

Accepted: November 22, 2019

Published: November 25, 2019

Copyright (c) 2019 by author(s) and Scientific Research Publishing Inc. This work is licensed under the Creative Commons Attribution International License (CC BY 4.0).

http://creativecommons.org/licenses/by/4.0/

\begin{abstract}
The icon design of mobile APPs could have a crucial effect on success of businesses since the initial contact with a business or service relies on the visual evaluation on the icons. It seems to be a challenge for designers to incorporate all the information within a tiny space of an icon, not to mention how making it attracted. Creativity has thus played its role in winning the game in the market of mobile APPs. Taking advantage of aesthetics, creativity not only makes a product more appealed but saleable in the markets. Similar to product design, icon design requires not only visual aesthetics, but all creative imperatives. In the competitive market, the fact is that there are only a few mobile APPs that have received awareness and survived every year since new product design with visual aesthetics and creativity is not without difficulty. It is the aim of the present research to examine the key factors of graphic design and the effect of creativity on the popularity of mobile APPs across different categories. The research intends to inspect the mobile APP's key characteristics and visualization. Theoretically, the research contributes to the mobile APPs literature through its findings on dimensional analysis and its relationships with creativity. In addition, results of the research provide useful insights into how companies or services adopt a strategic tactics to make their icon symbols more creative in the market of mobile APPs.
\end{abstract}

\section{Keywords}

Visual Aesthetics, Icon Design, Product Development, Creativity, Mobile APPs

\section{Introduction}

For business service, using mobile APPs is no longer an option but requires technology. The success of a service APP is fueled by its convenience and functionality, but the perception and evaluation of service rely heavily on the process during the service delivery [1]. Users of a mobile APP may have to associate the 
icon with its service quality due to lack of knowledge or experience using the service. As a fact, the mobile APPs have been downloaded intensively every day around the world, and consequently, the global revenue of mobile apps is estimated to grow up by $220 \%$ over the period of the next five years, from $\$ 36$ billion in 2015 to $\$ 79$ billion in 2020 [2]. In average, a person is using around 40 APPs in a month on the mobile devices [3]. Frequently selecting and installing APPs have become a norm for APP users and the icon design has therefore become an essential task for marketers to survive. Followed by a cognitive process, a consumer's perception and evaluation of APP icon are more visualized or image-oriented than brand-oriented due to the icon's intangibility. Creativity is therefore, providing a solution to the concern in APP design, but the questions of how to make it creative still remain no answer. It is the purpose of the study to better understand the cognitive process of selecting mobile APPs and effect of different components of creativity on APP design. Built on multi-dimensional aspects of creativity, the current study has the aims to focus on: first, investigating the elements of creativity on the APP icons; second, understanding of aesthetics and artistic design on the APP icons; third, examining the relationships of characteristics and elements of creativity of APP icons and the APP's performance.

\section{Research Questions}

There are countless numbers of mobile APPs available at any time on the Internet, while a relatively small number of the APPs are popular and used regularly. The decision of purchase or installation of the APPs may depend on the user's aesthetics judgment and creativity perception. Functionality, for example, would have never been evaluated until the visualized quality is appreciated by the users of mobile APPs. In other words, how to impress users from the first eye-contact becomes a challenge winning the game among the competitors in the market of mobile APPs. Being aware of and paying attention to a mobile APP is always challenging for the business of mobile APP service since there is only a tiny space for APP icon to fill up with unlimited possibility of aesthetical design. There are two research questions are derived from the above discussion:

1) How do users evaluate the icon of mobile APPs by using aesthetical elements?

2) How does creativity influence the users' judgment on the performance of mobile APPs?

\section{Literature Review}

\subsection{Arts and Aesthetics of Product Design}

The form of product design has drawn researchers' attention and contributed meaningful discussions over a decade. It has covered the topics from performance or marketing oriented [4] to art based visualization [5] [6]. Functioning as a substance of communication, product design is considered aesthetic artifact 
[7]. To be recognized and appreciated, an artwork with aesthetic quality has to be examined and judged through aesthetic values [8]. Nevertheless, the practical or functional quality is not less important than aesthetic quality and the judgement of aesthetics is not universal and there are no standards to assess. Artists can create a great piece of artwork which conveys artistic expressions, but one of the most significant appropriateness of artist work is its ability to evoke sensory pleasure with the aesthetic experience [9]. Based on the description, aesthetic or artistic expression can be found anywhere in the natural environment as long as the presence or appearance is beautiful or attracted. Rather than aesthetic experience, psychophysical properties are more easily observed and measured. Color, size, and shape, for example, are salient characteristics and have become common properties in product design. The artistic matters have such a pervasive attention to aesthetics on appearance that functionality could be easily overlooked [10]. By definition, the nature of design is innovative solution and aesthetics is its expression to be appreciated [11]. Appropriateness of design implies more comprehensive perspectives including not only aesthetics of art but also solutions of problems. In addition, the assessment of whether a product has a good design depends on the consumer's grasping its sensuous qualities. Strategically, marketers have to produce products more valuable other than the senses of aesthetics, which is evaluated subjectively. One of the most common issues assessing product design is perceived beauty. Unlike the subjective aesthetic judgment, the legal opinion of beauty usually associates with hedonic products such as smartphones and shoes. The attributes of design of these products can be perceived by communicating the quality of beauty to consumers [12]. As an effect of the aesthetic communication, appreciation of beauty requires the sense of attractiveness and sensory pleasure that can distinguish from other qualities such as utility. Such a salient element of design might have overweight over other elements such as functionality and novelty. A consumer may, therefore, first pay attention to the shape or color of a product and then evaluation may be concluded without taking a closer look. In the case, the sensual experience does not necessarily trigger cognitive process as expected. During the process of aesthetic communication, what intrigues academics and practitioners is how consumers perceive the qualities of product design by evaluating between subjective and objective apprehension.

\subsection{Creativity and Measure}

As a mental process of generating new ideas, creativity is a cognitive ability to produce creative both original and useful outcomes [13]. The concept of creativity suggests that either an idea, an act, or an outcome is a useful and effective response to evolutionary changes [14]. According to Torrance [15], there are four essential components of creativity: fluency, flexibility, novelty, and elaboration. First, creativity fluency is a measure of valuable innovation. Being able to generate a number of ideas or alternatives based on existing ideas is the minimum expectation of creativity fluency. The judgment of creativity fluency may rely on 
distinguished content of the message such as inspirational key words or surprising ideas [16]. There is no evidence to say an artifact with fluency until the desired outcomes are meaningful and relevant. Second, creativity flexibility refers to flexibility of thought [17]. To Guilford's assessment, creativity flexibility implies a variety of ideas across different categories after flexible or divergent thinking. Among the attempts to assess creativity, divergent thinking or looking at situations from multiple perspectives is important to measure the ability required for flexibility. In other words, creativity can be measured by divergent production which is associated with quantity of responses (i.e., how many, types, and detail of the responses). Third, novelty is another indispensable element of creativity to look at originality that is the character of being original. The perception of novelty is based on what has been produced before; in other words, novelty is to be known in contrast with an old or existing idea. Novelty does not inevitably have to accept something novel but something different from the object's antecedents. When a consumer is to determine her/his attention to a creative object, both objective and subjective factors may have influence on the selecting process [18]. Subjective novelty is the perception of newness, but objective novelty is an overall perception of rather an effect of different depth of historic memory. In the case of mobile APPs, a new icon design that has never been seen before is considered an objective novelty while another APP with regular design, but satisfying the emerging demands of the market should be subjective novelty. Last, elaboration is a matter of ability to add details and embellishment to an idea [15]. As a synonym of complexity, elaboration tends to measure the ability to add more ideas built on existing one. In conclusion, Guilford's [17] four measures of creativity have demonstrated how creative a work is and how to quantify creativity. However, the measures seem to be unable to conclude the relevance of the creative output and frequency of responses; therefore, it is not useful to measure the value of creativity.

\subsection{Meaningful, Novel, and Unpredictable Design}

Drawing on previous definitions of creativity, a more practical assessment of creativity can be better defined by the three distinguished concepts; that is, creativity has to be meaningful [19], novel [20], and unpredictable [21]. Meaningfulness acts as a foundation of creativity since a new product is presented in a way that is meaningful to the target customers [19]. A meaningful design distinguishes functionality from an artistic work. When a product design is perceived creative, the consumer's views are engaged in a clear sense of meaning and purpose. From the perspective of creativity relevance, consumers are expected to be inspired and motivated to connect a creative idea to product design. A creative work remains conscious and draws out powers that fuel hopes and possibilities because it takes the advantage of freedom and unlimited imagination [21]. Another key component of creativity is novelty which is most commonly used to assess creativity of products [20]. According to the author's conclusion, newness does not comprehend the nature of novelty. Indeed, novelty is 
a matter of invention that has to be unique [15]. However, what is so called novelty requires conformity to the past upon which novel things can be built. Rather than cognitive outcome as novelty, unpredictability is the intensity of felt amazement that can cause emotional states of surprise. An unexpected work which amazes viewers involves interests and impression as well [22]. Indeed, unpredictability acts as essence of creativity but not an independent attribute to creativity. Clarification of the overlapping on both meaningfulness and novelty is required when attempts to explain why and how a creative idea is unpredictable is expected.

\subsection{Creativity Evaluation on Mobile APPs}

A growing interest in creativity design for electronic products has made for the designers of mobile devices. Although the aesthetics of artifact's appearance has the focus based on the boundary between analytical and pragmatic aesthetics [23], none of studies has investigated in the aesthetical design of mobile APPs. Unlike a tangible product, a mobile APP is presented as an intangible image and untouchable icon within a tiny space on a mobile screen. The structure of the icon is so refrained from sketching beyond the specific space that creativity design of the icon has made it critical to success of the business service. Rather than the aesthetic experience with artifact work [24], what really intrigues both academics and practitioners is how an icon design of a mobile APP is perceived and evaluated as a creative work. The process from paying attention to creativity perception to a mere visualized icon is proposed to be completed through the viewer's awareness and cognitive processing of the three elements-meaningfulness, novelty, and unpredictability. The attractiveness of any combination of the three elements determines how the communication of aesthetic value is going on. Thus, it is believed that a consumer is still able to initiate an aesthetic interaction with the icon without experiencing functionality in advance. Indeed, the creativity evaluation is triggered by processing the information associated with cognitive inputs from perspectives of the consumer's personality, motivations, and emotions [25]. According to Locher [24], there are three types of information contributing to creativity evaluation: inherent, augmented, and functional information. In the case of mobile APPs, inherent information is acquired by observing the icon of a mobile APP. The kind of information is used to communicate the icon's basic characteristics such as shapes and names. Of the properties most saliently presented of a mobile APP is color. As visual cues, colors are indicative of signals associated with information from environment. Red color represents warm feeling or emergent condition while blue color may indicate cold weather or sad mood. The inherent information provides the connection between the APP's appearance and the user's pragmatic concerns. Augmented information, on the other hand, is a shared information based on the user's knowledge about it. Message, symbol, and pictures shown on an icon are examples indicating the content and action possibility of a mobile APP. There are specific symbols such as emotion stickers and well known signs that are fre- 
quently used in the design of mobile APPs. The augmented information does not guarantee creativity but it does facilitate the aesthetic interaction with creative works by sharing the same knowledge. The third type of information is functional information that informs the users the purpose of a product. Ideas to better design a mobile APP should be consistent with its original purpose--a better service with problem solving.

\subsection{Hypotheses}

Based on the literature mentioned above, the four hypotheses associated with creativity design of mobile APPs are stated below:

H1: Creativity acts as a mediator between the characteristics of mobile APPs and the users' ratings.

$\mathrm{H} 2$ : The impact of message on meaningfulness of creativity is weaker when functionality is absent than when it is presented on the icon.

H3: The impact of contrast on unpredictability of creativity is stronger when the detailed is presented than when it is absent on the icon.

H4: The impact of animation on novelty of creativity is stronger especially when the detailed is presented than when it is absent on the icon.

\section{Methodology}

\subsection{Research Design}

This study is conducted by an experimental design based on a $2 \times 2$ between-subjects randomized factorial design with two levels of creativity manipulated by the characteristics of creativity including message (no words/words), picture (no/yes), animation (no/yes), contrast (no/yes), harmony (no/yes), and details (simple/complicated). The experimental design is considered successful due to the confirmation of the effect of independent variables (elements of APP icon design) on the dependent variables (creativity factors and APP ratings). In this study, the design of an APP was evaluated based on factors including meaning, novelty, and unpredictability. The other extrinsic factors including color, shape, functionality, animation, harmony, and contrast are also included to exam their effect on creativity design.

\subsection{Research Sample}

To identify the key elements of creativity design on Mobile APPs, the investigator has adopted a sample frame by using secondary data collected from the leading companies/APPs on current markets (Apple Store and Google Play). The evaluation of the secondary data was processed by assessing the APP's availability, relevance, and sufficiency. The selection for the final list of mobile APPS is based on popularity and customers' feedback, regardless of the APP's performance. Any APP with less than 10,000 reviews in 2019 was excluded from the sample list. The sampling frame consists of 201 APPs selected from industries including social media, gaming, food service, language learning, and web service. 
There are around 30 APPs to be selected in each industry.

\subsection{Analysis Method}

To address the issue whether the measures of creativity had biased outcomes due to subjective judgment, two independent data sets were compared with t-test and no significant difference was found $(p=0.25)$. The t-test compares the group means of two independent groups to determine whether the associated population means are significantly different. To exam the interactional effects, general linear models (GLM) were conducted to adopt categorical variables in this study. GLM was useful as there were many dummy-code factors to be tested and by putting a categorical variable into fixed factors the interactions among all fixed factors came out easily to create interactional graphics. All the statistical tests have been conducted by using SPSS to analyze the data and report the findings.

\section{Results}

\subsection{Regression Models of Creativity and APP Rating}

In estimating the path coefficients between the ascendants and the descendants of creativity, multiple regression models were conducted and all of models showed significant results $(p<0.01)$. As shown in Figure 1 , the main effects of the key elements of creativity on the evaluations of creativity and the effects of creativity on APP rating have demonstrated the mediating role of creativity on APPs' rating scores. The standardized coefficients of variables including message (0.24), animation (0.25), and contrast (0.17) all have positive effects on the creativity of meaningfulness except that the variable of picture has negative effect $(-0.17)$. In examining the effects on novelty of creativity, message, animation, and details have been identified and all of their influences have been confirmed $(-0.34,0.15,0.18$, respectively). The results of last regression model of unpredictability have showed that contrast, harmony, and details are the three main characteristics positively affecting creativity $(0.23,0.21,0.23$, respectively). In the results of testing APPs' rating, unpredictability has the strongest explaining

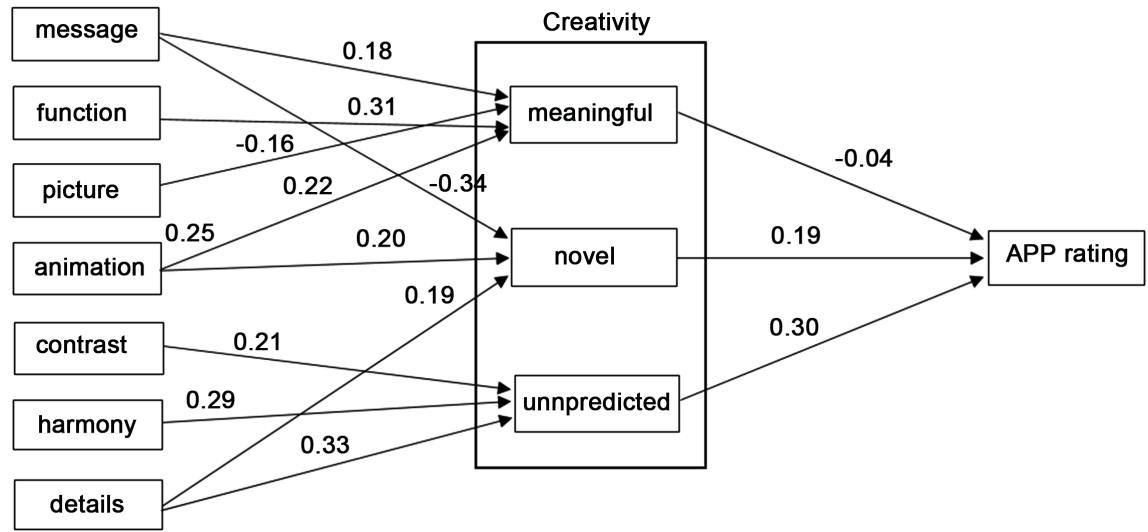

Figure 1. The framework of creativity design in mobile APPs. 
power on users' rating (0.30), and novelty has the moderate effect (0.19). However, meaningfulness is not as good as expected $(-0.04)$ and it has an only minimal negative effect on rating.

\subsection{Two-Way Interactions between the Elements of APP Design on Creativity}

H1 hypothesizes that the effect of APP design characteristics on APP rating toward the service provider would be mediated by creativity elements. To test the hypothesis, Baron and Kenny's [26] procedure is adopted and employed by the following steps: First of all, the independent variable should significantly affect the mediator. Second, the independent variable should significantly affect the dependent variable. Third, the mediator variable should affect the dependent variable when both the independent and the mediator variable are served as independent variables in the model. According to Baron and Kenny (1986), perfect mediation can hold as long as the independent variable has no effect on the dependent variable when the mediator is controlled. The results of the mediating tests show that creativity is a perfect mediator between the characteristics of icon design and APP's rating. Thus, $\mathrm{H} 1$ is supported.

The other two proposed hypotheses are tested by using the general linear model to determine the moderating effects of functionality and complication on meaningfulness and predictableness, respectively. $\mathrm{H} 2$ states the positive moderating effect of functionality and the result of Figure 2 shows that the interaction between message and functionality is significant $(\mathrm{F}=10.36, p<0.01) . \mathrm{H} 2$ is thus supported. The evidence indicates that functionality does matter and that

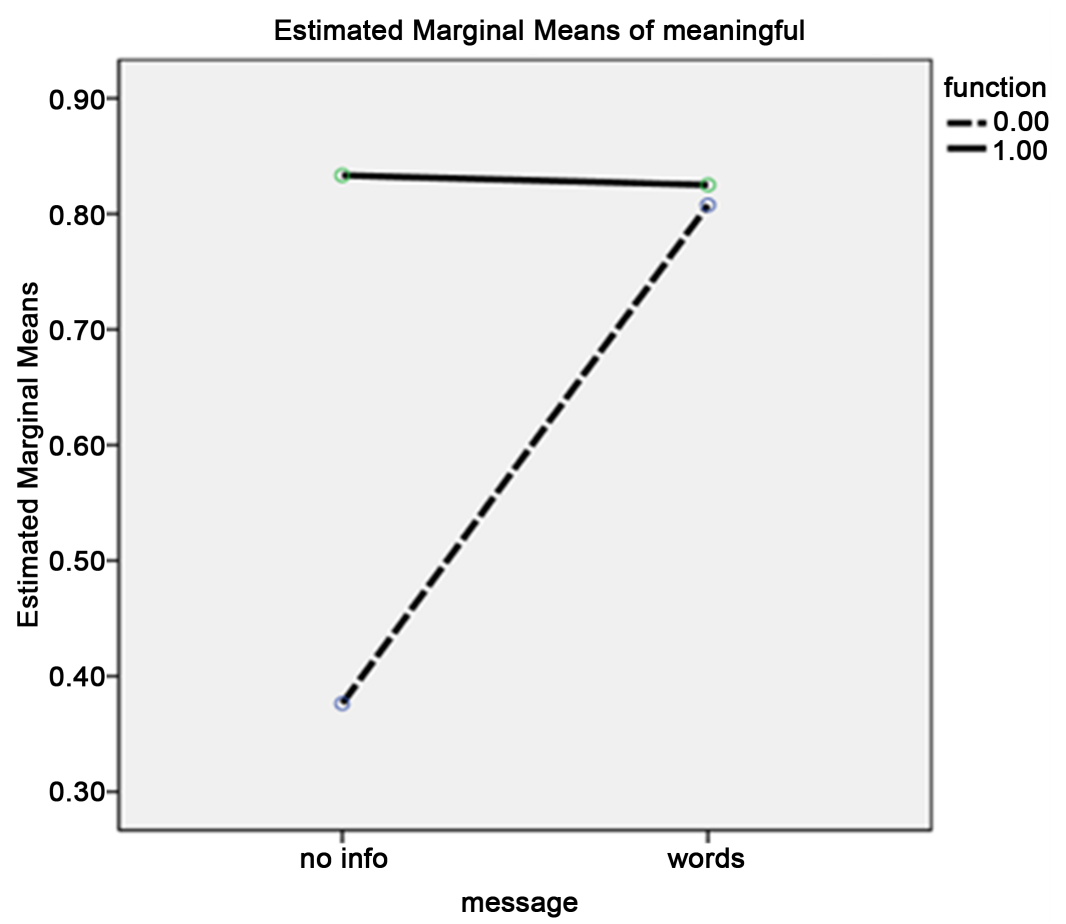

Figure 2. Interactions of function and message on meaningfulness. 
when an icon of a mobile APP has no words, no functionality will lower the perception of meaningfulness of creativity. Similarly, H3 is to exam the effect of contrast and details on unpredictability. The interaction of Figure 3 shows that contrast of icon design interacts with details of icon significantly. As the plot of interaction shows in Figure 3, an icon without contrast has the worse effect on unpredictability when the icon has detailed design. The interaction holds when there is contrast and the detailed is presented $(\mathrm{F}=4.32, p<0.05)$. Therefore, $\mathrm{H} 3$ is supported.

\subsection{Three-Way Interactions on Creativity}

To examine H4, message is added into the general linear model. Results show that there is a three-way interaction between message, animation, and details. In the both two-way interactions, an icon with words shows lower score on novelty in any case. However, the negative impact is alleviated when animation is presented. As shown in Figure 5, an icon with animation has similar effect on novelty when there are no words presented. In case of words presented, the icon is scored the lowest level of novelty (Figure 4). The negative impact of wording seems to be minimized when there is also a detailed design that can be found. Statistics in Figure 5 verify the moderating effect $(\mathrm{F}=5.52, p<0.05)$. H4 is thus supported.

\subsection{Implications and Summary of Results}

According to Figure 1, the characteristics of APP icon design have been identified to have interesting patterns of relationships with creativity. First of all,

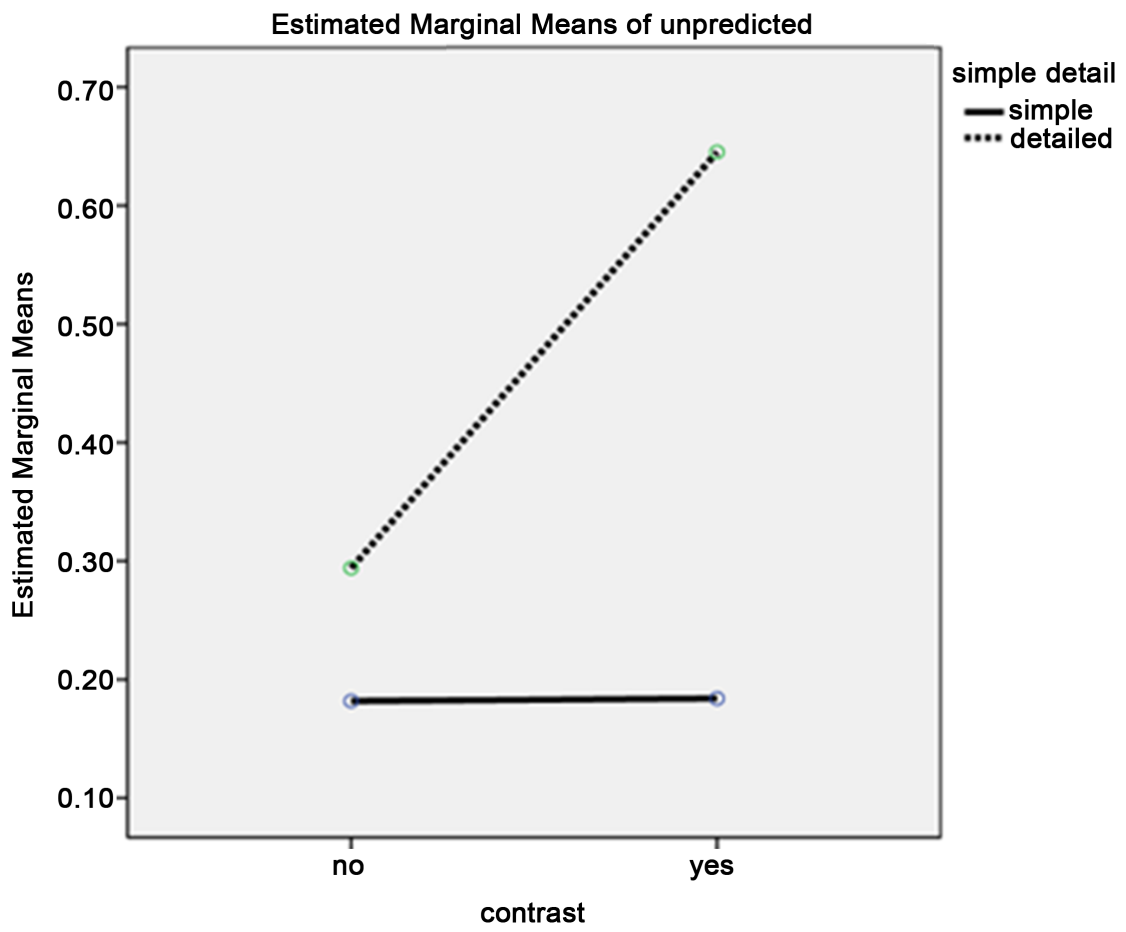

Figure 3. Interactions of details and contrast on unpredictability. 
Estimated Marginal Means of novel

at simpledetail $=$ simple

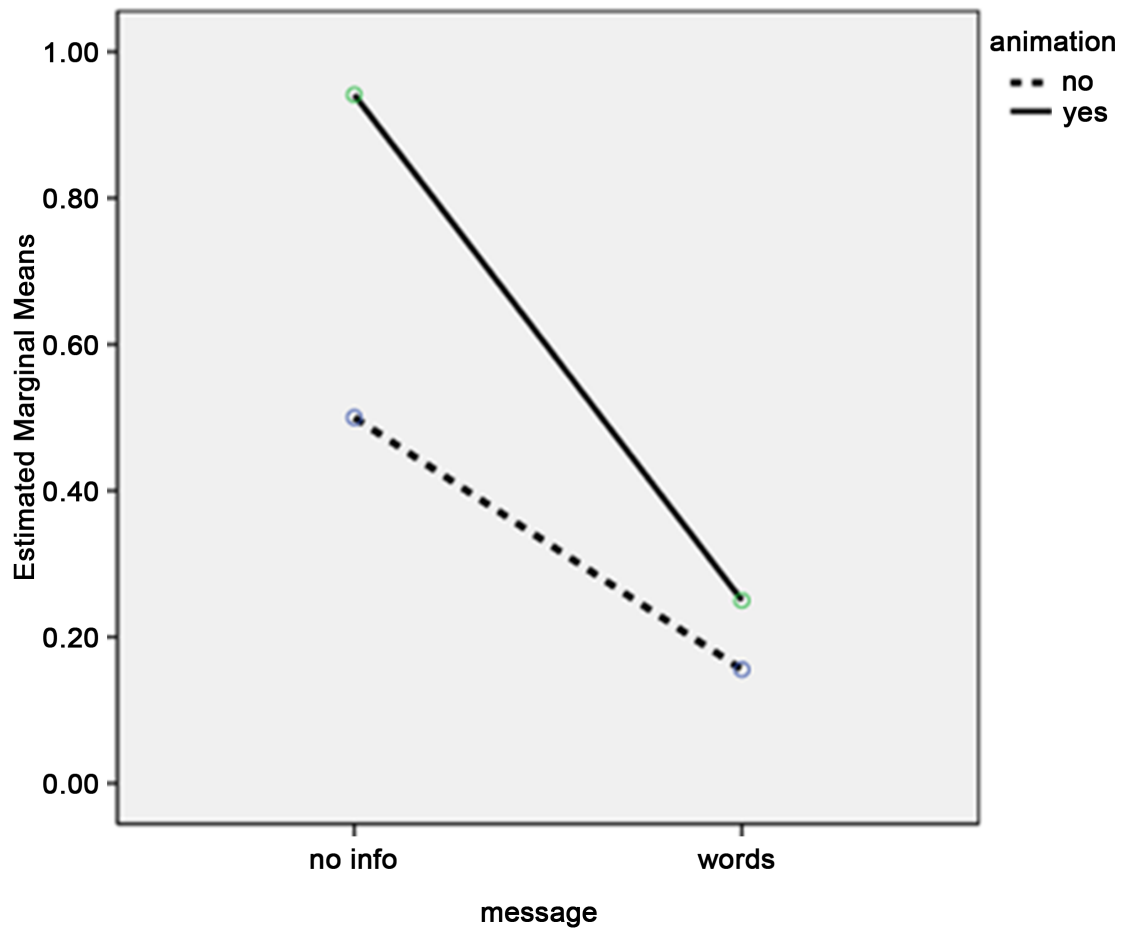

Figure 4. The three-way interactions of simplicity on novelty.

Estimated Marginal Means of novel

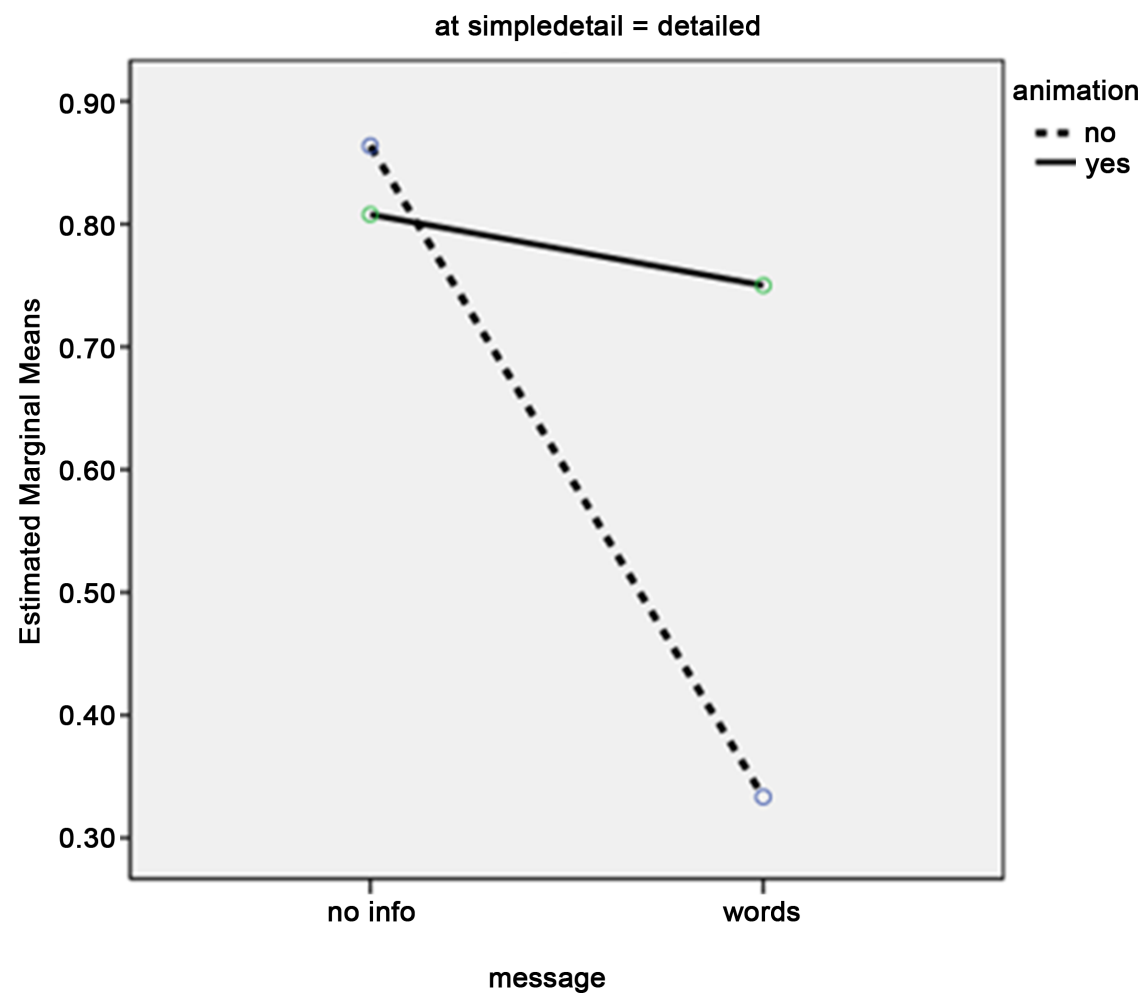

Figure 5. The three-way interactions of details on novelty. 
message have both positive and negative impacts on creativity. Meaningfulness is an essential element of creativity and perception of meaningfulness requires message that is meaningful [27]. Its positive relationship with meaningfulness explains that the APP design by adding words on an icon helps APP users to gain sense of the APP when observing it. However, regular message of words seems to be a bad signal of novelty. The negative relationship with novelty indicates the possibility of reproduction [28]. It means that a wording design is very common in commercial design and it is so easily recognized that making uniqueness or originality is almost impossible. In the two-way interactions, functionality is a key to the perception of meaningfulness. A sign of functionality makes APP users better understand the utility and purpose of the APP. Functionality can be the basic needs and wants of users since it provides a solution to problems [29]. In terms of unpredictability, contrast, harmony, and details all have significant explaining power on the dependent variable. What makes APP users impressed is actually an aesthetic work that combines all the three characteristics. As shown in Figure 3, compared to an icon without contrast design, contrast helps the perception of unpredictability only when the icon has more detailed content. In order to make an icon innovative and unpredictable, all of routine tasks or signs that associate with previous works should be avoid as observers of an icon are searching for anything relevant to it from their memory. Contrast and details can help creating variation in routine tasks by making the predictable unpredictable.

An interesting finding from the three-way interaction (Figure 4 and Figure 5) is that wording design can only bring a negative impact on creativity novelty. It is especially the case when an icon is presented as simplistic design. To deal with the problem of wording design, animation and details can enhance perceived novelty. Other characteristics such as pictures, contrast, and harmony are not likely to assist creating a novel design since APP users may have knowledge and image toward existing icon design. Such expectation won't help but only cause lower scores on novelty. Measuring novelty is obviously a challenge since "something is novel" means to introduce foreign elements into actuality. The problem of becoming novelty is that there is nothing novel if all the efforts to come up with a new idea similar to or based on something existing to the past [30]. In the case of APP icon design, creativity evaluation is so limited within a tiny space on a mobile screen that it is very common to see most icon designs with similarity in terms of color, shape, and image. Novelty, is therefore not a purely creative work, but an aesthetic and cognitive outcome. The summary of all two-way and three-way interactions between associated elements of APP icon design on all the three factors of creativity is listed on Table 1.

\section{Conclusion}

Creativity has been viewed as essential asset for businesses enabling intelligent capability to better compete in the knowledge-based economics [31]. The significant effect of creativity on APP's rating has been confirmed in this study and it 
Table 1. Summary of results of interactions.

\begin{tabular}{|c|c|c|c|c|c|c|c|}
\hline $\begin{array}{l}\text { Effect on } \\
\text { Creativity }\end{array}$ & Meaningfulness & Novelty & Unpredictableness & $\begin{array}{l}\text { Two-way on } \\
\text { Meaningful }\end{array}$ & $\begin{array}{l}\text { Two-way on } \\
\text { Unpredicted }\end{array}$ & $\begin{array}{l}\text { Three } \\
\text { on N }\end{array}$ & \\
\hline function & $10.85^{\star *}$ & $\mathrm{n} / \mathrm{a}$ & & $12.06^{\star *}$ & $\mathrm{n} / \mathrm{a}$ & \multicolumn{2}{|c|}{$\mathrm{n} / \mathrm{a}$} \\
\hline message & 1.66 & $21.7^{* *}$ & & $9.59^{*}$ & $\mathrm{n} / \mathrm{a}$ & $21.7^{* *}$ & \\
\hline animation & 6.84 & 6.61 & & $\mathrm{n} / \mathrm{a}$ & $\mathrm{n} / \mathrm{a}$ & 6.61 & $5.52^{\star}$ \\
\hline Sim/detail & $\mathrm{n} / \mathrm{a}$ & 6.7 & 3.59 & $\mathrm{n} / \mathrm{a}$ & $11.67^{* *}$ & 6.7 & \\
\hline contrast & $\mathrm{n} / \mathrm{a}$ & $\mathrm{n} / \mathrm{a}$ & 5.87 & $\mathrm{n} / \mathrm{a}$ & $4.42^{*}$ & $\mathrm{n}$ & \\
\hline harmony & $\mathrm{n} / \mathrm{a}$ & $\mathrm{n} / \mathrm{a}$ & 5.89 & $\mathrm{n} / \mathrm{a}$ & $\mathrm{n} / \mathrm{a}$ & $\mathrm{n}$ & \\
\hline picture & 2.23 & $\mathrm{n} / \mathrm{a}$ & & $\mathrm{n} / \mathrm{a}$ & $\mathrm{n} / \mathrm{a}$ & $\mathrm{n}$ & \\
\hline
\end{tabular}

${ }^{*}$. F value is significant at the 0.01 level (2-tailed). ${ }^{*}$. F value is significant at the 0.05 level (2-tailed).

suggests that a creative design dose enhances ratings of APPs. Taking advantage of aesthetics, a creative APP design is not just an artistic work but it is fueled by its capacity for problem-solving. In other words, aesthetics is not a sufficient condition for building creativity but the baseline of creativity should be consisted of novelty and functionality [32]. Artwork could be of creativity since it explores the purpose of originality but there is no guarantee of novelty. It is the purpose of this study to re-exam the key components of creativity design and to demonstrate how creativity works as overlapping area by adding the three elements-meaningfulness, novelty, and unpredictability into the diagram of creativity concept. Unfortunately, the pattern of building creativity is still inconclusive since creativity can never be applied in the same way to any design. To catch customers' eye contact and remain interested, the APP icon design is suggested to have an unpredictable impression as the first step to creativity design. This pragmatic approach to design can be achieved by well balancing between the characteristics of contrast and details. Once an initial impression of an icon is formed, the attention to the icon's meaning or functionality is the focus during the interaction between the creativity perception and aesthetic evaluation. Message and animation, for example, provide icon information that can activate a customer's memory of relevant experience. Further, signs or symbolic associations of functionality convey the utility or value of an APP that can be perceived based on the customer's existing knowledge about the functionality. In other words, icon design is meaningful because it is interpreted based on what it was. However, impression with meaningfulness does not guarantee creativity. The most challenge work of creativity is to measure novelty [30]. Quantifying novelty requires cognitive capacity to utilize both memory retention and memory improvement. It is a brain accessing to the learned experience. In the case of APP design, an icon is perceived novel because it is unique and has never been seen alike before. It may be extremely difficult to make an APP icon purely novel since there are more than two millions of APPs available in the market. There must be something similar or common characteristic that was experienced and shared in the users' memory. Animation and details, based on the findings, can 
help create novel works that can be easily perceived deviated from what it was in memory.

Contributions and impacts of the research are considered to be made due to several reasons listed below. First, there are relatively few articles investigating icon design of mobile APPs by using the concept of creativity. The study attempts to provide a framework to incorporate critical elements of icon design with creativity evaluations. It could help APP or graphic designers to better interact with the APP users. Second, a competitive advantage over other APP providers can be gained through a more attractive, impressive, and memorable APP icon design. The finding of this study can really help service providers to be successful on the mobile markets. Third, the study may have the answers of why mobile APPs fail frequently. Mistakes are usually made behind unsuccessful APPs but consumers seldom blame it for what it looks or issues of graphic design and aesthetics once they have installed them. The biggest problem is that most of APPs have never had the chance to be selected due to unattractiveness. It is also the purpose of this study to best visualize APPs by adding more impressive or eye-catching elements to increase the users' interest and downloads of the APP. In conclusion, the study aims to exam the key components of creativity in APP icon design. The result provides a pragmatic approach for mobile APP designers and service providers. Built on aesthetics, appealing of creativity design may be better understood by adding the three components--meaningfulness, novelty, and unpredictability. The focal point of measuring creativity conveys a diagram of overlapping between the three components. The proposed diagram indicates that there is no guarantee of creativity except the presence of overlapping. Other characteristics than what have been used in this study may also contribute moderating effect since there are no universal ways to make works creative. For further research of creativity design, cultural or linguistic effects could be a promising direction and provides a richer potential for building creativity.

\section{Conflicts of Interest}

The author declares no conflicts of interest regarding the publication of this paper.

\section{References}

[1] Parasuraman, A., Zeithaml, V.A. and Berry, L.L. (1998) SERVQUAL: A Multiple-Item Scale for Measuring Consumer Perceptions of Service Quality. Journal of Retailing, 64, 12-40.

[2] Statista, Worldwide Mobile App Revenues in 2015, 2016 and 2020. https://www.statista.com/statistics/269025/worldwide-mobile-app-revenue-forecast

[3] App Annie, The Average Smartphone User Accessed Close to 40 Apps Per Month in 2017. https://www.appannie.com/en/insights/market-data/apps-used-2017/

[4] Bloch, P.H. (1995) Seeking the Ideal Form: Product Design and Consumer Re- 
sponse. Journal of Marketing, 59, 16-29.

https://doi.org/10.1177/002224299505900302

[5] Hagtvedt, H. and Patrick, V.M. (2008) Art Infusion: The Influence of Visual Art on the Perception and Evaluation of Consumer Products. Journal of Marketing Research, 45, 379-389. https://doi.org/10.1509/jmkr.45.3.379

[6] Hüttl-Maack, V. (2018) Visual Art in Advertising: New Insights on the Role of Consumers' Art Interest and Its Interplay with the Hedonic Value of the Advertised Product. Journal of product and Brand Management, 17, 262-276.

https://doi.org/10.1108/JPBM-02-2017-1424

[7] Yamamoto, M. and Lambert, D.R. (1994) The Impact of Product Aesthetics on the Evaluation of Industrial Products. Journal of Product Innovation Management, 11, 309-324. https://doi.org/10.1111/1540-5885.1140309

[8] Osborne, H. (1968) Aesthetics and Art Theory: An Historical Introduction. E. P. Dutton and Company, New York.

[9] Wang, Y.J., Cruthirds, K.W., Axinn, C.N. and Guo, C. (2013) In Search of Aesthetics in Consumer Marketing: An Examination of Aesthetic Stimuli from the Philosophy of Art and the Psychology of Art. Academy of Marketing Studies Journal, 17, 37-55.

[10] Creusen, M.E.H., Veryzer, R.W. and Schoormans, J.P.L. (2010) Product Value Importance and Consumer Preference for Visual Complexity and Symmetry. European Journal of Marketing, 49, 1437-1452. https://doi.org/10.1108/03090561011062916

[11] Shirwaiker, R.A. and Okudan, G.E. (2008) Triz and Axiomatic Design: A Review of Case-Studies and a Proposed Synergistic Use. Journal of Intelligent Manufacturing, 19, 33-47. https://doi.org/10.1007/s10845-007-0044-6

[12] Toufani, S., Stanton, J.P. and Chikweche, T. (2017) The Importance of Aesthetics on Customers' Intentions to Purchase Smartphones. Marketing Intelligence \& Planning, 35, 316-338. https://doi.org/10.1108/MIP-12-2015-0230

[13] Saul, M. and Leikin, R. (2010) Intercultural Aspects of Creativity: Challenges and Barriers. Mediterranean Journal for Research in Mathematics Education, 9, 1-9.

[14] Runco, M.A. (2004) Creativity. Annual Review of Psychology, 55, 657-687. https://doi.org/10.1146/annurev.psych.55.090902.141502

[15] Torrance, E.P. (1974) Torrance Tests of Creative Thinking: Directions Manual and Scoring Guide. Ginn, Lexington, MA.

[16] Steinhart, Y. (2012) All that Glitters Is Not Gold: The Dual Effect of Activation Technique in Advertising. Marketing Letters, 23, 195-208.

https://doi.org/10.1007/s11002-011-9147-0

[17] Guilford, J.P. (1950) Creativity. American Psychologist, 5, 444-454. https://doi.org/10.1037/h0063487

[18] Surkova, I. (2012) Towards a Creativity Framework. Society and Economy, 34, 115-138. https://doi.org/10.1556/SocEc.2011.0013

[19] Im, S. and Workman, J.P. (2004) Market Orientation, Creativity, and New Product Performance in High-Technology Firms. Journal of Marketing, 68, 114-132. https://doi.org/10.1509/jmkg.68.2.114.27788

[20] Sarkar, P. and Chakrabarti, A. (2011) Assessing Design Creativity. Design Studies, 32, 348-383. https://doi.org/10.1016/j.destud.2011.01.002

[21] Boden, M. (1992) The Creative Mind: Myths and Mechanisms. Basic Books, New York. 
[22] Meyer, W., Reisenzein, R. and Schützwohl, A. (1997) Towards a Process Analysis of Emotions: The Case of Surprise. Motivation and Emotion, 21, 251-274. https://doi.org/10.1023/A:1024422330338

[23] Petersen, M., Iversen, O., Krogh, P. and Ludvigsen, M. (2004) Aesthetic Interaction: A Pragmatist's Aesthetics of Interactive Systems. Proceedings of 5 th Conference on Designing Interactive Systems. Processes, Practices, Methods, and Technique, ACM Press, Cambridge, MA, 269-276. https://doi.org/10.1145/1013115.1013153

[24] Locher, P., Overbeeke, K. and Wensveen, S. (2010) Aesthetic Interaction: A Framework. Design Issues, 26, 70-79. https://doi.org/10.1162/DESI a 00017

[25] Shavitt, S. (1989) Products, Personalities, and Situations in Attitude Functions: Implications for Consumer Behavior. Advances in Consumer Research, 16, 300-305.

[26] Baron, R.M. and Kenny, D.A. (1986) The Moderator-Mediator Variable Distinction in Social Psychological Research: Conceptual, Strategic, and Statistical Considerations. Journal of Personality and Social Psychology, 51, 1173-1182. https://doi.org/10.1037//0022-3514.51.6.1173

[27] Chaudhary, R. and Panda, C. (2018) Authentic Leadership and Creativity: The Intervening Role of Psychological Meaningfulness, Safety and Work Engagement. International Journal of Productivity and Performance, 67, 2071-2088. https://doi.org/10.1108/IJPPM-02-2018-0082

[28] Madden, C. (2004) Creativity and Arts Policy. Journal of Arts Management, Law, and Society, 34, 133-139. https://doi.org/10.3200/JAML.34.2.133-140

[29] Ocker, R., Fjermestad, J., Hiltz, S.R. and Johnson, K. (1998) Effects of Four Modes of Group Communication on the Outcomes of Software Requirements Determination. Journal of Management Information Systems, 15, 99-118. https://doi.org/10.1080/07421222.1998.11518198

[30] Jerzyk, E. (2014) Creativity Techniques in Marketing-Manager's Expertise Compared to Its Practical Application. International Journal of Arts \& Sciences, 7, 99-106.

[31] Lau, K.W. (2016) Understanding Creativity Competency for Organizational Learning: A Study of Employees' Assumptions on Creativity Competency in Creative Industry. Journal of Management Development, 35, 1198-1218. https://doi.org/10.1108/JMD-12-2015-0174

[32] Sadi, M.A. and Al-Dubaisi, A.H. (2008) Barriers to Organizational Creativity: The Marketing Executives' Perspective in Saudi Arabia. Journal of Management Development, 27, 574-599. https://doi.org/10.1108/02621710810877839 